\title{
Canada's new ethical guidelines for research with humans: a critique and comparison with the United States
}

\section{Joseph Millum PhD}

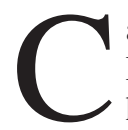
anada's Tri-Council Policy Statement: Ethical conduct for research involving humans, first published in 1998, has recently been updated. ${ }^{1}$ The US Department of Health and Human Services has just issued an Advance Notice of Proposed Rulemaking that would substantially change the 20-year-old Common Rule governing most federally funded research involving human participants. ${ }^{2} \mathrm{~A}$ comparison of the two countries' systems for protecting human research participants is therefore timely. This analysis situates the Canadian system in an international context, with particular attention to its similarities and differences to the US system and their shared challenges going forward with their changes.

\section{Systems of oversight for research with humans}

Prior review of research proposals by a research ethics committee according to legally binding standards is the primary means used around the world to protect research participants. In Canada and the United States, the institutions that conduct research are responsible for its review. As a result, most academic centres have their own research ethics committee - a research ethics board in Canada or an institutional review board in the US. Similar institutional models are followed by other developed countries, such as Australia and Japan. By contrast, regional models - in which a research ethics committee reviews all the research conducted in a particular geographic area - are common in Europe.

In Canada, any institution that receives funding from one of the three federal granting agencies - the Canadian Institutes of Health Research, the Social Sciences and Humanities Research Council, and the Natural Sciences and Engineering Research Council of Canada must ensure that all research involving humans conducted at that institution complies with the Tri-Council Policy Statement. Health Canada also requires that sponsors of clinical trials of drugs and devices obtain approval from a research ethics board, and two provinces (Quebec, and Newfoundland and Labrador) require ethics review for some or all of the research that takes place within them. ${ }^{3,4}$ However, the TriCouncil Policy Statement is the primary source of concrete guidance regarding the ethical oversight of research with humans in Canada. From its inception, the statement has been intended to be a "living, evolving document that reflects developments in research and research ethics." ${ }^{5}$ Hence the current revisions.

In the US, most research involving human participants funded by federal government agencies is subject to the Common Rule - a set of regulations delineating the requirements for review by an institutional review board. ${ }^{6}$ Similar rules apply to research regulated by the Food and Drug Administration (FDA). ${ }^{7}$ Although US institutions could decline to apply the Common Rule to research that does not receive federal funding, relatively few do so. ${ }^{8}$ The reforms proposed in the recent Advance Notice of Proposed Rulemaking have two goals. First, to improve the effectiveness of the system of federal oversight, for example, by reducing the amount of time spent reviewing low-risk research and by allowing only one institutional review board of record for multisite studies. ${ }^{9}$ Second, to enhance protections for research participants, for example, by imposing uniform standards of security of data and requiring all research at institutions receiving funding from Common Rule agencies to follow the Common Rule (just as the Tri-Council Policy Statement does for Canada).

In both systems, then, ethics review of research is necessary if funding is received from the federal

\section{KEY POINTS}

- The updated Tri-Council Policy Statement has nearly doubled in length and improves on its 1998 predecessor.

- The recent US Advance Notice of Proposed Rulemaking suggests substantial changes to the Common Rule.

- Canada and the United States have similar systems of ethical review with similar problems.

- The problems that have not been addressed thus far mostly concern the application and scope of rules, not their content.
Competing interests: None declared.

This article has been peer reviewed.

Correspondence to: Dr. Joseph Millum, millumj@cc.nih.gov

CMAJ 2012. DOI:10.1503 /cmaj.111217 
government or regulatory approval of new drugs and devices is sought. Again, this differs from many other countries, where all research with human participants within their borders may be required to undergo review. For example, the European Clinical Trials Directive applies to all clinical trials, irrespective of source of funding or other contact with government bodies..$^{10}$

The institutional model of review has the advantages that members of the research ethics committee are more likely to be familiar with the research they review, monitoring of ongoing research is easier and it is possible to impose institutional sanctions for violations by investigators. However, this model has several drawbacks. First, conflicts of interest are more likely because the institution hosting the research ethics committee has an interest in the research proceeding, and members of the research ethics committee may be colleagues of the researchers. ${ }^{11}$ Second, an increasing amount of research now takes place at multiple sites. ${ }^{12}$ In Canada and the US, because institutions are held liable for regulatory breaches, this usually entails a research ethics committee at each site reviewing the research proposal. Multiple reviews take up time and resources, and researchers complain of inconsistent judgments from research ethics committees that mandate minor changes without improving protections for research participants. . $^{13,14}$

Use of government funding or contact with regulatory agencies as the way to ensure ethics review carries the risk of ethically problematic research falling through the cracks. For example, pharmaceutical companies may conduct research that is not part of marketing applications, and experimentation with surgical techniques may not use novel drugs or devices. Stories of people being enrolled in risky research without protections has led to calls in the US for a nationwide law requiring ethics review. ${ }^{15,16}$

This method of ensuring ethics review can also lead to research falling under multiple sets of regulations. For example, the US federal government funds a substantial amount of research involving human participants abroad, including in Canada (e.g., in 2010 the National Institutes of Health gave nearly US\$64 million in direct grants to Canadian institutions). ${ }^{17}$ Because of the funding source, the researchers must follow the Common Rule; but at Canadian institutions they must simultaneously follow the Tri-Council Policy Statement. The same concern arises when researchers from Canadian institutions conduct research abroad.

Where possible, the Tri-Council Policy Statement and the Common Rule do attempt to address these problems. The Tri-Council Policy
Statement has considered conflicts of interest, including conflicts of interest for members of research ethics boards, since $1998 .{ }^{18}$ The updated statement extends its analysis of conflicts of interest and the measures that should be taken to address them, for instance, by addressing conflicts of interest for institutions and institutional officials. With regard to multiple reviews, both Canadian and US rules permit institutions to rely on outside research ethics committees, although relatively few institutions currently use this option. ${ }^{19}$ However, experiments with centralizing review - such as the US National Cancer Institute's Central Institutional Review Board and the Ontario Cancer Research Ethics Board - have had broadly positive results. ${ }^{20,21}$ An analysis of centralized and noncentralized review in five English-speaking countries suggested that centralizing at least the administrative aspects of ethics review is helpful in reducing delays and excessive work from multisite trials. ${ }^{22}$ Moreover, one key change in the US Advance Notice of Proposed Rulemaking would require there to be just one institutional review board of record for all domestic sites involved in a multisite study. Multijurisdictional research has its own chapter in the updated Tri-Council Policy Statement, which includes extensive discussion of a range of different models for review by research ethics boards of multisite research.

The problem of having both sets of regulations apply to research in Canada funded by the US government could also be solved under the current regulations. For research at institutions in foreign countries that follow different procedures for protecting human participants, the Common Rule states the following:

if a department or agency head determines that the procedures prescribed by the institution afford protections that are at least equivalent to those provided in this policy [the Common Rule], the department or agency head may approve the substitution of the foreign procedures in lieu of the procedural requirements provided in this policy. ${ }^{23}$

However, despite the development of a method for determining whether a set of procedures offers "equivalent protections," this option has never been taken. ${ }^{24}$

The problems just noted stem from structural features of the systems of review. In some instances, documents like the Tri-Council Policy Statement can be helpful. For example, a future revision could follow the Advance Notice of Proposed Rulemaking and require that only one research ethics board conduct most of the review for multisite studies. In other instances, however, legislative action would be needed to change the 
systems in ways that would address the problems. For example, as it stands, the Tri-Council Policy Statement does all that it can to ensure that potentially risky research undergoes review - the Tri-Council agencies do not have the power to require review at institutions where they do not fund research. That would require provincial or national legislation.

\section{The process of ethical review}

Like the ethics review systems in other countries, the Canadian and US systems have provoked criticism from researchers for inappropriately applying biomedical models to research from other disciplines and for requiring low-risk research to undergo excessive scrutiny.

The Common Rule was written in response to abuses by biomedical researchers and designed to regulate biomedical research. Nonetheless, it applies to any research that involves obtaining data through "intervention or interaction" with living persons, and review by institutional review boards of humanities and social science research is now common. The Tri-Council Policy Statement was explicitly intended to cover nonbiomedical research. However, in both countries, some social science researchers complain that a biomedical model is inappropriately imposed on their discipline with a potentially chilling effect on important research. ${ }^{25,26}$ The updated Tri-Council Policy Statement places greater emphasis than its predecessor on distinguishing the standards that should apply to different types of research; for example, it now has separate chapters discussing qualitative research and clinical trials. It is also the result of an extensive process of consultation, including with academics in the social and behavioural sciences, and, as a Tri-Council statement, has been endorsed by the Social Sciences and Humanities Research Council.

Both jurisdictions exempt some research with humans from review, and countenance an expedited or delegated form of review for some research involving "minimal risk" whereby the review is conducted by just one or two members of a research ethics committee. Nevertheless, full review by a research ethics committee is common even for research that falls into one of these categories. ${ }^{27,28}$ One of the changes proposed by the US Advance Notice of Proposed Rulemaking would attempt to address this problem by excusing a wider category of studies from review, including all studies whose risks are mostly informational, provided that they adhere to strict standards for data security and confidentiality. Crucially, researchers engaged in excused research would be permitted to begin research immediately after registering their study with the institutional review board, so as to avoid the current situation where many institutions require some prior review of purportedly exempt studies to ensure that they are exempt.

The updated Tri-Council Policy Statement continues to place more emphasis on flexibility than the Common Rule (although the Advance Notice of Proposed Rulemaking offers some ways to make the scrutiny of research proposals more proportionate to levels of risk than at present). The updated statement consistently emphasizes the importance of a "proportionate approach to research ethics review" 29 according to which the most risky research receives the "most intensive scrutiny, time and resources." Moreover, individual institutions are granted considerable leeway in deciding how to institute this proportionate approach, who may carry out delegated reviews and so forth. This flexibility is a model for others to follow, and Canadian institutions should make the most of it - the resources for ethics review are always limited, so they should be used to focus on the research most likely to raise ethical concerns. ${ }^{31}$

\section{The Tri-Council Policy Statement}

Its significantly greater length allows the TriCouncil Policy Statement to address many more ethical issues than the Common Rule. Although guidance on specific questions is periodically issued by the FDA or the Office for Human Research Protections, the US does not have regulatory requirements covering so many key issues. ${ }^{32}$ The updated Tri-Council Policy Statement mostly consists of changes or additions, which have nearly doubled its size. ${ }^{33}$ These include further guidance on research involving Aboriginal people, incidental findings relevant to participants' health, conflicts of interest and research during emergencies. The additions reflect ethical issues that have become much more prominent over the last decade. The updated statement also casts its net more widely to cover more than just the protection of research participants. For instance, like the 2008 Declaration of Helsinki, it now requires the registration of clinical trials before recruitment begins. ${ }^{34}$

The core principles of the Tri-Council Policy Statement have been radically revised. According to the first version of the statement, respect for human dignity was the foundational principle of research ethics. Somewhat confusingly, it was also one of eight guiding ethical principles. The updated version consolidates these principles to three - respect for persons, concern for welfare, and justice. These correspond to the principles 
underlying the US regulations as stated in the Belmont Report..$^{35}$ The updated Tri-Council Policy Statement purports to retain "respect for human dignity" as its "underlying value." However, the concept does not do any real work independent of the core principles.

The new approach is an improvement: the three principles better reflect the content of ordinary moral thought. Ethical dilemmas that people face in all areas of life - not just in research — involve the consideration of how to respect people's rights, balance benefits and harms, and treat people fairly. Moreover, none of these three principles can be assimilated to any of the others; for example, it is important to respect someone's autonomous decisions, even if they are likely to negatively affect his or her welfare. Hence, these three principles are both central and basic to moral thought.

\section{Substantive disagreements}

The original Tri-Council Policy Statement and the US regulations differed on several issues, most notably on the use of placebo controls and research with children. These disagreements remain. The US FDA permits placebo controls even when there exists an effective treatment for the condition being studied in a wide range of cases in which use of placebo is deemed scientifically necessary. ${ }^{36}$ The updated Tri-Council Policy Statement is much more restrictive. The only instance it suggests in which it would be permissible to randomly assign participants to placebo when a proven treatment for those participants exists is when "patients have provided an informed refusal of established effective therapy" before recruitment. ${ }^{37}$ This is strict in comparison to even the Declaration of Helsinki, which now allows the use of placebos when an effective treatment exists if there are "compelling and scientifically sound methodological reasons" for using placebo, and participants will not be at risk of serious harm. ${ }^{38}$

The updated Tri-Council Policy Statement permits research with children only when it poses minimal net risk to participants. This is consistent with international guidelines such as the Declaration of Helsinki. ${ }^{39}$ In the US, children may be enrolled in research that involves a "minor increase over minimal risk" with no prospect of direct benefit if the research is expected to produce important knowledge about the participants' disorder or condition. ${ }^{40}$ There is even provision for the approval of riskier research in exceptional circumstances. ${ }^{41}$

With these rules strictly applied, one would expect these differences to lead to different research being conducted in the two countries and to impede some collaborative research. If they have not, it might illuminate the practice of review by research ethics committees to investigate why.

\section{Looking forward}

The updated Tri-Council Policy Statement improves on the guidance of its predecessor and expands on ethical issues that were less prominent in 1998. It should also prove a useful resource in the US, where institutional review boards sometimes lack clear guidance on the novel ethical issues they face. However, the biggest problems for both systems concern the implementation of the rules, not their content. Many of these problems - such as conflicts of interest in research ethics committees, underreview and overreview - are related to the institution-based model of ethical review in both countries. For the most part, guidance and regulatory resources, like the Tri-Council Policy Statement, address these problems, but their suggested solutions require work by institutions and government agencies to implement them effectively. Either greater efforts to implement them are needed, or stricter rules - like those now proposed for multisite review in the US must be imposed.

\section{References}

1. Tri-council policy statement: ethical conduct for research involving humans. Ottawa (ON): Canadian Institutes of Health Research, Natural Sciences and Engineering Research Council of Canada, and Social Sciences and Humanities Research Council of Canada; 2010.

2. Food and Drug Administration and the Office of the Secretary. Human subjects research protections: enhancing protections for research subjects and reducing burden, delay, and ambiguity for investigators. Washington (DC): US Department of Health and Human Services; 2011.

3. Arts 20 and $21 \mathrm{CCQ}$.

4. Health Research Ethics Authority Regulations under the Health Research Ethics Authority Act, NL R 57/11.

5. Government of Canada. About the TCPS. Panel on Research Ethics. Available: www.pre.ethics.gc.ca/eng/panel-group/faq /tcps-eptc/ (accessed 2011 Oct. 3).

6. Protections of human subjects, 45 CFR part 46, subpart A (1991). Revised Jan. 15, 2009; effective July 14, 2009.

7. Food and Drugs, 21 CFR parts 50 and 56 (2010). Chapter I: Food and Drug Administration, Department of Health and Human Services. Subchapter A: General. Revised as of Apr. 1, 2011.

8. Thomson J, Elgin C, Hyman D, et al. Research on human subjects. academic freedom and the institutional review board. Washington (DC): American Association of University Professors; 2006.

9. Emanuel EJ, Menikoff J. Reforming the regulations governing research with human subjects. N Engl J Med 2011;365:1145-50.

10. EC, Directive 2001/20/EC of the European Parliament and of the Council of 4 April 2001 on the approximation of the laws, regulations and administrative provisions of the Member States relating to the implementation of good clinical practice in the conduct of clinical trials on medicinal products for human use, [2001] OJ, L 121/34

11. Wolf LE, Zandecki J. Conflicts of interest in research: how IRBs address their own conflicts. IRB 2007;29:6-12.

12. McWilliams R, Hoover-Fong J, Hamosh A, et al. Problematic variation in local institutional review of a multicenter genetic epidemiology study. JAMA 2003;290:360-6.

13. Fost N, Levine RJ. The dysregulation of human subjects research. JAMA 2007;298:2196-8. 
14. Hébert P, Saginur R. Research ethics review: Do it once and do it well. CMAJ 2009;180:597-8.

15. Gunsalus CK. An examination of issues presented by proposals to unify and expand federal oversight of human subject research. In: Ethical and policy issues in research involving human participants. Volume II: commissioned papers. Washington (DC): National Bioethics Advisory Commission; 2001.

16. Ethical and policy issues in research involving human participants. Volume I: report and recommendations of the National Bioethics Advisory Commission. Washington (DC): National Bioethics Advisory Commission; 2001.

17. National Institutes of Health. Research Portfolio Online Reporting Tools (RePORT). Washington (DC): US Department of Health and Human Services; 2011. Available: http://project reporter.nih.gov/reporter.cfm (accessed 2011 Oct. 3).

18. Tri-Council policy statement: ethical conduct for research involving humans. Ottawa (ON): Canadian Institutes of Health Research, Natural Sciences and Engineering Research Council of Canada, Social Sciences and Humanities Research Council of Canada; 1998 (with 2000, 2002 and 2005 amendments).

19. Sobolski GK, Flores L, Emanuel EJ. Institutional review board review of multicenter studies. Ann Intern Med 2007;146:759.

20. Wagner TH, Murray C, Goldberg J, et al. Costs and benefits of the National Cancer Institute Central Institutional Review Board. J Clin Oncol 2010;28:662-6.

21. Chaddah MR; Ontario Institute for Cancer Research. The Ontario Cancer Research Ethics Board: a central REB that works. Curr Oncol 2008;15:49-52.

22. Fitzgerald MH, Phillips PA. Centralized and non-centralized ethics review: a five nation study. Account Res 2006;13:47-74.

23. Protections of human subjects, 45 CFR $\$ 46.101(\mathrm{~h})$. Revised Jan 15, 2009; effective July 14, 2009.

24. Lavery JV, McDonald M, Meslin EM. Research ethics across the 49th parallel: the potential value of pilot testing "equivalent protections" in Canadian research institutions. Health Law Rev 2005; 13:86-96

25. Social Sciences and Humanities Research Ethics Special Working Committee. Giving voice to the spectrum. Interagency Advisory Panel and Secretariat on Research Ethics; 2004. Available: www.sfu.ca/ palys/SSHWC-GivingVoice-2004.pdf (accessed 2011 Dec. 6)

26. Bledsoe $\mathrm{CH}$, Sherin B, Galinsky AG, et al. Regulating creativity: research and survival in the IRB iron cage. Northwest Univ Law Rev 2007; 101:593-641.

27. Wagner RM. Ethical review of research involving human subjects: When and why is IRB review necessary? Muscle Nerve 2003;28:27-39.

28. Bell J, Whiton J, Connelly S. Evaluation of NIH implementation of Section 491 of the Public Health Service Act, mandating a program of protection for research subjects. Arlington (VA): James Bell Associates; 1998.

29. Tri-Council policy statement: ethical conduct for research involving humans [article 6.12]. Ottawa $(\mathrm{ON})$ : Canadian Institutes of Health Research, Natural Sciences and Engineering
Research Council of Canada, Social Sciences and Humanities Research Council of Canada; 2010.

30. Tri-Council policy statement: ethical conduct for research involving humans [article 2.9]. Ottawa (ON): Canadian Institutes of Health Research, Natural Sciences and Engineering Research Council of Canada, Social Sciences and Humanities Research Council of Canada; 2010.

31. Millum J, Menikoff J. Streamlining ethical review. Ann Intern Med 2010;153:655-7.

32. Office for Human Research Protections. Policy and guidance. Washington (DC): US Department of Health and Human Services. Available: www.hhs.gov/ohrp/policy/index.html (accessed 2011 Dec. 6).

33. Tri-Council policy statement: ethical conduct for research involving humans. [table of concordance]. Ottawa (ON): Canadian Institutes of Health Research, Natural Sciences and Engineering Research Council of Canada, Social Sciences and Humanities Research Council of Canada; 2010.

34. World Medical Association. Declaration of Helsinki. FerneyVoltaire (France): The Association; 2008

35. The National Commission for the Protection of Human Subjects of Biomedical and Behavioral Research. The Belmont report: ethical principles and guidelines for the protection of human subjects of research. Washington (DC): The Commission; 1979.

36. Temple R, Ellenberg SS. Placebo-controlled trials and activecontrol trials in the evaluation of new treatments. Part 1: ethical and scientific issues. Ann Intern Med 2000;133:455-63.

37. Tri-Council policy statement: ethical conduct for research involving humans [article 11.2]. Ottawa $(\mathrm{ON})$ : Canadian Institutes of Health Research, Natural Sciences and Engineering Research Council of Canada, Social Sciences and Humanities Research Council of Canada; 2010.

38. World Medical Association. Declaration of Helsinki [principle 32]. Ferney-Voltaire (France): The Association; 2008

39. World Medical Association. Declaration of Helsinki [principle 27]. Ferney-Voltaire (France): The Association; 2008

40. Protections of human subjects, 45 CFR $\$ 46.406$. Revised Jan. 15, 2009; effective July 14, 2009.

41. Protections of human subjects, 45 CFR \$46.407. Revised Jan. 15, 2009; effective July 14, 2009

Affiliation: From the Department of Bioethics and Fogarty International Center, National Institutes of Health, Bethesda, Md.

Acknowledgements: The author thanks Kirstin Borgerson and Jim Lavery for helpful comments on an earlier draft of this manuscript.

Disclaimer: The opinions expressed are those of the author and do not reflect the position or policy of the National Institutes of Health, the Public Health Service or the Department of Health and Human Services.

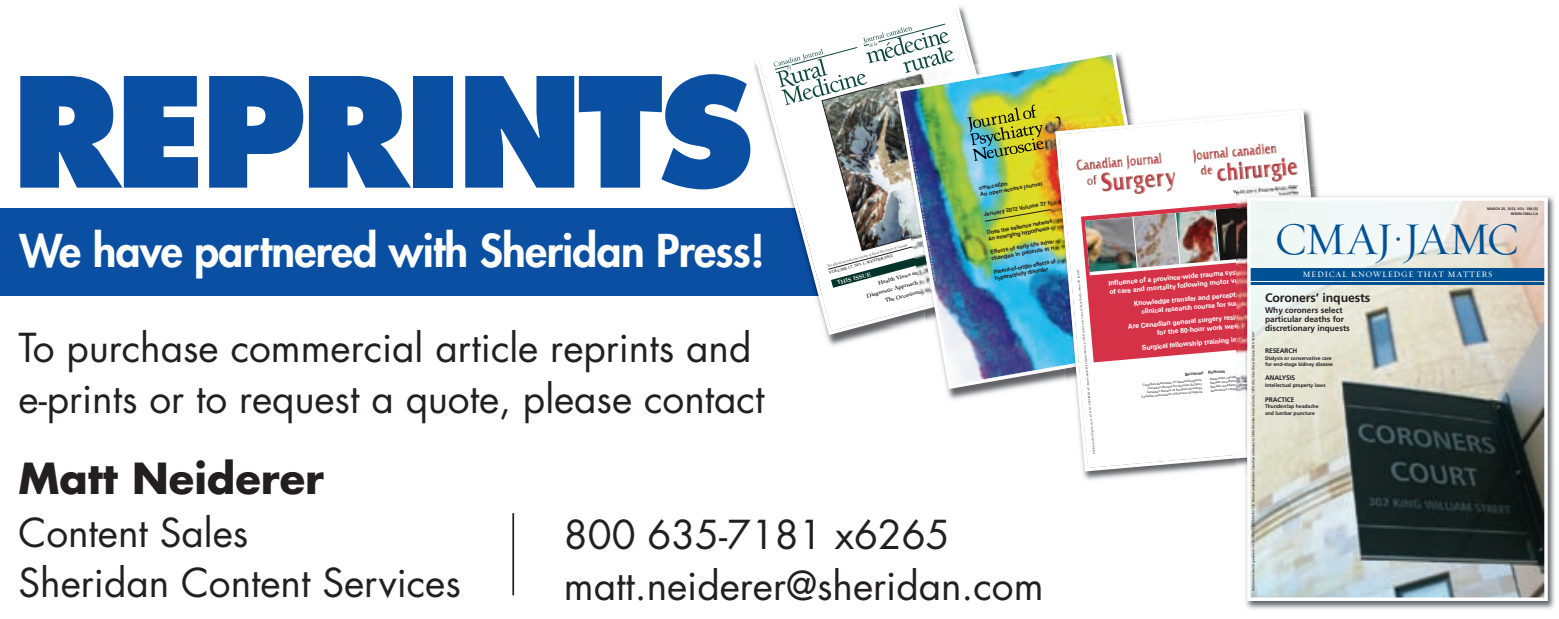

